\title{
Active Space Selection Based on Natural Orbital Occupation Numbers From N-Electron Valence Perturbation Theory
}

\author{
Abhishek Khedkar and Michael Roemelt* \\ Lehrstuhl für Theoretische Chemie, Ruhr-Universität Bochum, D-44780 Bochum, Germany \\ and Max-Planck Institut für Kohlenforschung, Kaiser-Wilhelm Platz 1, D-45470 Mülheim \\ an der Ruhr, Germany \\ E-mail: michael.roemelt@theochem.rub.de \\ Supporting Information
}

${ }^{*}$ To whom correspondence should be addressed 


\section{A: Contributions to the First Order Interactive Space (FOIS) Density from various subspaces}

In this section we shall look through the contributions to the first order density deriving from

the various $S_{l}^{(k)}$ subspaces. Definitions of $\mathbf{T}_{\mathbf{a b}}, \gamma, \mathbf{K}_{\mathbf{i j}}$ etc. here are limited to the particular contribution while the following definitions are used throughout.

$$
\begin{aligned}
\Gamma_{t u}^{p r} & =\left\langle\Psi_{m}^{(0)}\left|a_{p}^{\dagger} a_{r}^{\dagger} a_{t} a_{u}\right| \Psi_{m}^{(0)}\right\rangle \\
\Gamma_{u}^{t} & =\left\langle\Psi_{m}^{(0)}\left|E_{u}^{t}\right| \Psi_{m}^{(0)}\right\rangle .
\end{aligned}
$$

$\epsilon_{l}^{(k)}$ in all of the following are evaluated as described in the original work of Angeli et al.

External-External part, $\mathrm{D}_{\mathrm{ef}}^{(\mathrm{k}, \mathrm{l}), \mathrm{ext}}$

Contributions from $\mathrm{S}_{\mathrm{ij}, \mathrm{ab}}^{(\mathbf{0})}$

$$
\mathbf{D}^{(i j, a b), \text { ext }}=\sum_{i \geq j}\left(\tilde{\mathbf{T}}_{i j} \mathbf{T}_{i j}^{\dagger}+\tilde{\mathbf{T}}_{j i} \mathbf{T}_{j i}^{\dagger}\right)+\sum_{i} \overline{\mathbf{T}}_{i i} \mathbf{T}_{i i}^{\dagger}
$$

where

$$
\begin{array}{rlr}
\tilde{\mathbf{T}}_{i j} & =4 \cdot \mathbf{T}_{i j}-2 \cdot \mathbf{T}_{j i} & \text { and } \\
\overline{\mathbf{T}}_{i i} & =2 \cdot \mathbf{T}_{i i} & \text { and } \\
T_{i j, a b} & =\frac{(i a \mid j b)}{\epsilon_{a}+\epsilon_{b}-\epsilon_{i}-\epsilon_{j}} &
\end{array}
$$




\section{Contributions from $\mathrm{S}_{\mathrm{i}, \mathrm{ab}}^{(-1)}$}

$$
\begin{aligned}
\mathbf{D}^{(i, a b) \operatorname{ext}} & =\sum_{i} \sum_{t, u} \Gamma_{t}^{u}\left(2 \cdot \mathbf{T}_{i u} \mathbf{T}_{i t}^{\dagger}+2 \cdot \mathbf{T}_{u i} \mathbf{T}_{t i}^{\dagger}-\mathbf{T}_{i u} \mathbf{T}_{t i}^{\dagger}-\mathbf{T}_{u i} \mathbf{T}_{i t}^{\dagger}\right) \\
& =\sum_{i} \sum_{t, u} \Gamma_{t}^{u}\left(\tilde{\mathbf{T}}_{i u} \mathbf{T}_{i t}^{\dagger}+\tilde{\mathbf{T}}_{u i} \mathbf{T}_{t i}^{\dagger}\right)
\end{aligned}
$$

where

$$
\begin{aligned}
\tilde{\mathbf{T}}_{i t} & =2 \cdot \mathbf{T}_{i t}-\mathbf{T}_{t i} \\
T_{i t, a b} & =\frac{(i a \mid t b)}{\epsilon_{a}+\epsilon_{b}-\epsilon_{i}+\epsilon_{i, a b}}
\end{aligned}
$$

and

$$
\Gamma_{t}^{u}=\left\langle\Psi_{m}^{(0)}\left|E_{t}^{u}\right| \Psi_{m}^{(0)}\right\rangle
$$

The effective ionization potential

$$
\epsilon_{i, a b}=\frac{1}{N_{i, a b}^{(-1)}}\left\langle\Psi_{m}^{(0)}\left|\hat{V}_{i, a b}^{(-1) \dagger}\left[\hat{H}_{v}, \hat{V}_{i, a b}^{(-1)}\right]\right| \Psi_{m}^{(0)}\right\rangle
$$

is evaluated as described in the original work of Angeli and coworkers.

Contributions from $\mathrm{S}_{\mathrm{ij}, \mathbf{a}}^{(+\mathbf{1})}$

$$
\begin{aligned}
D_{e f}^{(i j, a), e x t} & =\sum_{i j} \sum_{t u}\left[\frac{2(e i \mid j t)[2(f i \mid j t)-(f j \mid i t)]}{\Delta_{i j, e} \Delta_{f, i j}}\right. \\
& \left.+\frac{\Gamma_{u}^{t}(f i \mid j t)\left[\left[\frac{1}{2}(e j \mid i u)-2(e i \mid j u)\right]+\frac{1}{2}(f j \mid i t)(e i \mid j u)\right]}{\Delta_{i j, e} \cdot \Delta_{f, i j}}\right]
\end{aligned}
$$


where

$$
\Delta_{i j, e}=\epsilon_{e}+\epsilon_{i j, e}^{(+1)}-\epsilon_{i}-\epsilon_{j}
$$

Here, $\epsilon_{i j, e}^{(+1)}$ is constructed as described by Angeli et al.

Contributions from $\mathrm{S}_{\mathrm{ab}}^{(-2)}$

$$
\mathbf{D}_{e f}^{(a b), e x t}=\frac{1}{2} \sum_{t u} \sum_{v w}\left[\bar{\gamma}_{u t w v}\left[\mathbf{T}_{t u} \mathbf{T}_{v w}^{\dagger}+\mathbf{T}_{u t} \mathbf{T}_{w v}^{\dagger}\right]\right]-\sum_{t u} \sum_{v} \Gamma_{u}^{t}\left[\mathbf{T}_{t v} \mathbf{T}_{v u}^{\dagger}+\mathbf{T}_{v t} \mathbf{T}_{u v}^{\dagger}\right]
$$

where

$$
\begin{aligned}
& T_{t u, a f}=\frac{(f u \mid t a)}{\epsilon_{a}+\epsilon_{f}-\epsilon_{a f}^{(-2)}} \\
& \epsilon_{a f}^{(-2)}=\frac{1}{N_{a f}^{(-2)}} \cdot\left\langle 0\left|V^{+}\left[H_{v}, V\right]\right| 0\right\rangle
\end{aligned}
$$

$\epsilon_{a f}^{(-2)}$ is constructed as described by Angeli et al.

$$
\bar{\gamma}_{u t w v}=2 \Gamma_{w v}^{u t}+\delta_{t w} \cdot \Gamma_{v}^{u}
$$

\section{Contributions from $\mathbf{S}_{\mathbf{i}, \mathbf{a}}^{(\mathbf{0})}$}

$$
\begin{aligned}
D_{e f}^{(i, a), e x t}= & \sum_{i} \sum_{t u} \sum_{v w}\left[\gamma \left[2 T_{t u}(i, f) T_{v w}(i, e)-K_{t u}(i, f) T_{v w}(i, e)\right.\right. \\
& \left.\left.-T_{t u}(i, f) K_{v w}(i, e)\right]-\bar{\gamma}\left[K_{t u}(i, f) K_{v w}(i, e)\right]\right] \\
& \sum_{i} \sum_{t u}\left[\left[\sum_{v} \Gamma_{t}^{u}\left[2 K_{v u}(i, f) K_{v t}(i, e)+K_{t u}(i, f) K_{v v}(i, e)\right]\right]+\right. \\
& \left.\Gamma_{t}^{u}\left[2 H(f, i) T_{t u}(i, e)-H(f, i) K_{u t}(i, e)+2 T_{t u}(i, f) H(e, i)-K_{t u}(i, f) H(e, i)\right]\right] \\
& +\sum_{i} 2 H(f, i) H(e, i)
\end{aligned}
$$


where $\mathrm{T}, \mathrm{H}$ and $\mathrm{K}$ are defined as follows:

$$
\begin{aligned}
& T_{t u}(i, f)=\frac{(f i \mid t u)}{\epsilon_{i, f}^{(0)}+\epsilon_{a}-\epsilon_{i}}, K_{t u}(i, f)=\frac{(f u \mid i t)}{\epsilon_{i, f}^{(0)}+\epsilon_{a}-\epsilon_{i}}, \\
& K_{v w}(i, e)=\frac{(e w \mid i v)}{\epsilon_{i, e}^{(0)}+\epsilon_{a}-\epsilon_{i}}, K_{u t}(i, e)=\frac{(e t \mid i u)}{\epsilon_{i, e}^{(0)}+\epsilon_{a}-\epsilon_{i}} \\
& \epsilon_{i, a}^{(0)}=\frac{1}{N_{i, a}^{(0)}}\left\langle 0\left|V^{+}\left[H_{v}, V\right]\right| 0\right\rangle, H(f, i)=\frac{h_{f i}^{e f f}}{\epsilon_{i, f}^{(0)}+\epsilon_{a}-\epsilon_{i}}
\end{aligned}
$$

$\epsilon_{i, a}^{(0)}$ is constructed as described by Angeli et al. also,

$$
\begin{aligned}
& \gamma=\gamma_{w t v u}=2 \Gamma_{v u}^{w t}+\delta_{t v} \Gamma_{u}^{w} \\
& \bar{\gamma}=\gamma_{t w v u}=2 \Gamma_{v u}^{t w}+\delta_{w v} \Gamma_{u}^{t}
\end{aligned}
$$

Contributions from $\mathrm{S}_{\mathrm{a}}^{(-1)}$

$$
\begin{aligned}
D_{e f}^{(a), e x t}= & \sum_{t u} \sum_{v w} \sum_{x y}\left[\tilde{\Gamma}_{w u v}^{y x t} K_{t u}(v, f) K_{w x}(y, e)\right] \\
& +\sum_{t u} \sum_{v w}\left[\gamma T_{u v}(w, e) H(t, f)+\bar{\gamma} K_{t u}(v, f) H(w, e)\right] \\
& +\sum_{t u} \Gamma_{u}^{t} H(t, f) H(u, e)
\end{aligned}
$$

where $\mathrm{H}, \mathrm{T}$, and $\mathrm{K}$ are defined as follows:

$$
\begin{gathered}
\tilde{\Gamma}_{s t u}^{p q r}=\Gamma_{s t u}^{p q r}+2 \delta_{s q} \Gamma_{t u}^{p r}+2 \delta_{r s} \Gamma_{u t}^{p q}+2 \delta_{r t} \Gamma_{s u}^{p q}+\delta_{r t} \delta_{s q} \Gamma_{u}^{p} \\
\Gamma_{t u}^{p r}=\left\langle\Psi_{m}^{(0)}\left|a_{p}^{\dagger} a_{r}^{\dagger} a_{t} a_{u}\right| \Psi_{m}^{(0)}\right\rangle \\
\Gamma_{u}^{t}=\left\langle\Psi_{m}^{(0)}\left|E_{u}^{t}\right| \Psi_{m}^{(0)}\right\rangle
\end{gathered}
$$




$$
\begin{aligned}
& T_{u v}(w, e)=\frac{(u v \mid w e)}{\epsilon_{e}-\epsilon_{e}^{(-1)}}, K_{t u}(v, f)=\frac{(t v \mid u f)}{\epsilon_{f}-\epsilon_{f}^{(-1)}} \\
& K_{w x}(y, e)=\frac{(w y \mid x e)}{\epsilon_{e}-\epsilon_{e}^{(-1)}}, H(t, f)=\frac{h_{t f}^{e f f}}{\epsilon_{f}-\epsilon_{f}^{(-1)}} \\
& \epsilon_{a}^{(-1)}=\frac{1}{N_{a}^{(-1)}} \cdot\left\langle 0\left|V^{+}\left[H_{v}, V\right]\right| 0\right\rangle
\end{aligned}
$$

$\epsilon_{a}^{(-1)}$ is constructed as described by Angeli et al.

$$
\begin{aligned}
& \gamma=\gamma_{u w v t}=2 \Gamma_{v t}^{u w}+\delta_{w v} \Gamma_{t}^{u} \\
& \bar{\gamma}=\gamma_{w t u v}=2 \Gamma_{u v}^{w t}+\delta_{t u} \Gamma_{v}^{w}
\end{aligned}
$$

Internal-Internal part, $\mathrm{D}_{\mathrm{mn}}^{(\mathrm{k}, \mathrm{l}) \text {,int }}$

\section{Contributions from $\mathrm{S}_{\mathrm{ij}, \mathrm{ab}}^{(0)}$}

$$
\begin{aligned}
D_{m n}^{(i j, a b), i n t}= & \sum_{i} \sum_{a b}\left[2 T_{m i}(a, b) T_{n i}(b, a)-4 T_{m i}(a, b) T_{n i}(a, b)\right] \\
& +\sum_{i j} \sum_{a b} \delta_{m n}\left[4 T_{i j}(a, b) T_{i j}(a, b)-2 T_{i j}(b, a) T_{i j}(a, b)\right]
\end{aligned}
$$

where

$$
T_{i j, a b}=\frac{(i a \mid j b)}{\epsilon_{a}+\epsilon_{b}-\epsilon_{i}-\epsilon_{j}}
$$

Contributions from $\mathrm{S}_{\mathrm{i}, \mathrm{ab}}^{(-1)}$

$$
\begin{aligned}
D_{m n}^{(i, a b), i n t}= & \sum_{i} \sum_{a b} \sum_{t u} \Gamma_{t}^{u}\left[\delta_{m n} T_{i t}(a, b)\left[4 T_{i u}(a, b)-2 T_{i u}(b, a)\right]\right. \\
& \left.+T_{m t}(a, b)\left[-2 T_{n u}(a, b)+T_{n u}(b, a)\right]\right]
\end{aligned}
$$


where

$$
\begin{aligned}
& T_{i t, a b}=\frac{(i a \mid t b)}{\epsilon_{a}+\epsilon_{b}-\epsilon_{i}-\epsilon_{i, a b}^{(-1)}} \\
& \Gamma_{t}^{u}=\left\langle\Psi_{m}^{(0)}\left|E_{t}^{u}\right| \Psi_{m}^{(0)}\right\rangle
\end{aligned}
$$

The effective ionization potential

$$
\epsilon_{i, a b}=\frac{1}{N_{i, a b}^{(-1)}}\left\langle\Psi_{m}^{(0)}\left|\hat{V}_{i, a b}^{(-1) \dagger}\left[\hat{H}_{v}, \hat{V}_{i, a b}^{(-1)}\right]\right| \Psi_{m}^{(0)}\right\rangle
$$

is evaluated as described in the original work of Angeli et al.

Contributions from $\mathrm{S}_{\mathrm{ij}, \mathrm{a}}^{(+\mathbf{1})}$

$$
\begin{array}{r}
D_{m n}^{(i j, a), i n t}=\sum_{i j} \sum_{t u} \sum_{a} \Gamma_{u}^{t}\left[\delta_{m n} T_{i j}(t, a)\left[-4 T_{i j}(u, a)+2 T_{j i}(u, a)\right]\right. \\
+T_{i m}(t, a)\left[2 T_{i n}(u, a)-T_{n i}(u, a)\right] \\
\left.+T_{m i}(t, a)\left[2 T_{n i}(u, a)-T_{i n}(u, a)\right]\right] \\
+\sum_{i j} \sum_{t} \sum_{a}\left[\delta_{m n} . T_{i j}(t, a)\left[8 T_{i j}(t, a)-4 . T_{j i}(t, a)\right]\right. \\
+T_{i m}(t, a)\left[-4 T_{i n}(t, a)+2 T_{n i}(t, a)\right] \\
\left.+T_{m i}(t, a)\left[-4 T_{n i}(t, a)+2 T_{i n}(t, a)\right]\right]
\end{array}
$$

where

$$
T_{i j}(t, a)=\frac{(i t \mid j a)}{\epsilon_{a}+\epsilon_{i j, a}^{(1)}-\epsilon_{i}-\epsilon_{j}}
$$




\section{Contributions from $\mathrm{S}_{\mathrm{ij}}^{(+2)}$}

$$
\begin{gathered}
D_{m n}^{(i j), i n t}=\sum_{t u} \sum_{i j}\left[\delta_{m n} T_{i j}(t, u)\left(4 T_{i j}(t, u)-2 T_{i j}(u, t)\right)\right. \\
\left.+T_{m i}(t, u)\left(-4 T_{n i}(t, u)+2 T_{n i}(u, t)\right)\right] \\
\sum_{t u} \sum_{v} \sum_{i j}\left[\delta_{m n} \Gamma_{u}^{t} T_{i j}(u, v)\left(-4 T_{i j}(t, v)+T_{i j}(v, t)\right)\right. \\
+\Gamma_{u}^{t}\left(T_{m i}(u, v)\left[2 T_{n i}(t, v)-\frac{1}{2} T_{n i}(v, t)\right]\right. \\
\left.+T_{m i}(v, u)\left[2 T_{n i}(v, t)-\frac{1}{2} T_{n i}(t, v)\right]\right) \\
\sum_{t u} \sum_{v w} \sum_{i j} \bar{\Gamma}_{v w}^{t u}\left(\delta_{m n} T_{i j}(u, t) T_{i j}(w, v)\right. \\
\left.-\frac{1}{2}\left[T_{m i}(u, t) T_{n i}(w, v)+T_{m i}(t, u) T_{n i}(v, w)\right]\right)
\end{gathered}
$$

where

$$
\begin{aligned}
T_{i j}(t, u) & =\frac{(i t \mid j u)}{\epsilon_{i j}^{(2)}-\epsilon_{i}-\epsilon_{j}} \\
\bar{\Gamma}_{v t}^{u w} & =2 \Gamma_{v t}^{u w}+\delta_{w v} \Gamma_{t}^{u}
\end{aligned}
$$

Contributions from $\mathbf{S}_{\mathbf{i}, \mathbf{a}}^{(\mathbf{0})}$

$$
\begin{aligned}
D_{m n}^{(i, a), i n t}=\sum_{t u} \sum_{v w} \sum_{i a} \Gamma_{v u}^{w t}( & 4 \delta_{m n} T_{t u}(i, a) T_{v w}(i, a)-2 T_{t u}(m, a) T_{v w}(n, a) \\
& -2 \delta_{m n} K_{t u}(i, a) T_{v w}(i, a)+T_{v w}(n, a) K_{t u}(m, a) \\
& -2 \delta_{m n} T_{t u}(i, a) K_{v w}(i, a)+T_{t u}(m, a) K_{v w}(n, a) \\
& \left.-2 \delta_{m n} K_{v t}(i, a) K_{w u}(i, a)+K_{w u}(m, a) K_{v t}(n, a)\right)
\end{aligned}
$$




$$
\begin{aligned}
+\sum_{t u} \sum_{v} \sum_{i a} \Gamma_{u}^{t}( & 4 \delta_{m n} K_{v t}(i, a) K_{v u}(i, a)+2 \delta_{m n} . K_{t u}(i, a) K_{v v}(i, a) \\
& -2 K_{v t}(n, a) K_{v u}(m, a)-K_{t u}(m, a) K_{v v}(n, a) \\
& +H(i, a) \delta_{m n}\left[8 T_{t u}(i, a)-2 K_{u t}(i, a)-2 K_{t u}(i, a)\right] \\
& +H(n, a)\left[K_{t u}(m, a)-2 T_{t u}(m, a)\right] \\
& \left.+H(m, a)\left[K_{u t}(n, a)-2 T_{t u}(n, a)\right]\right) \\
& +\sum_{i a} 4 \delta_{m n} H^{2}(i, a)-2 \sum_{a} H(m, a) H(n, a) \\
\Gamma_{t u}^{p r} & =\left\langle\Psi_{m}^{(0)}\left|a_{p}^{\dagger} a_{r}^{\dagger} a_{t} a_{u}\right| \Psi_{m}^{(0)}\right\rangle \\
& \\
& \\
& H(i, a)=\frac{h_{i a}^{e f f^{\prime}}}{\epsilon_{i, a}^{(0)}+\epsilon_{a}-\epsilon_{i}} \\
K_{i, a}(i, a)=\frac{(i a \mid t u)}{\epsilon_{i, a}^{(0)}+\epsilon_{a}-\epsilon_{i}} & \\
& \\
& \\
& \\
& \\
&
\end{aligned}
$$




\section{B: CASSCF active natural orbitals and their occupancies}

\section{Hieber anion}
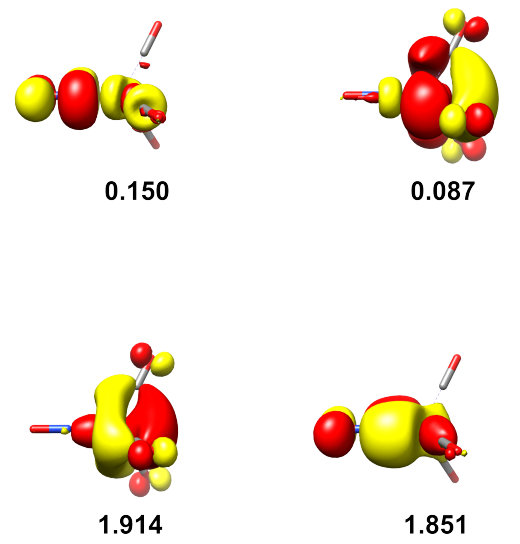
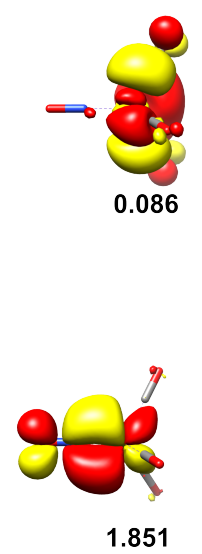
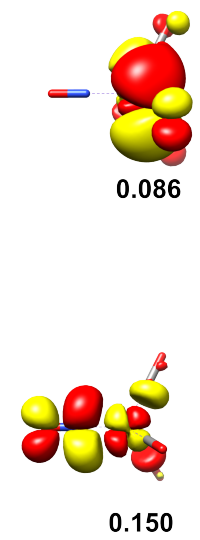
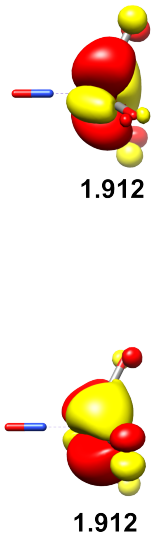

Figure S1: The $(10,10)^{\alpha}$ active orbitals for the singlet state of complex $\mathbf{1}$
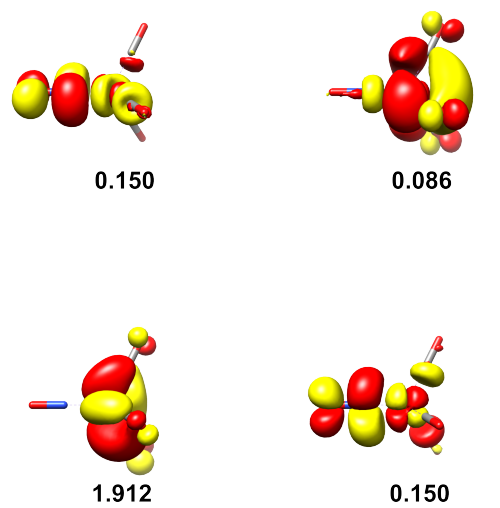

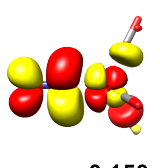

0.150
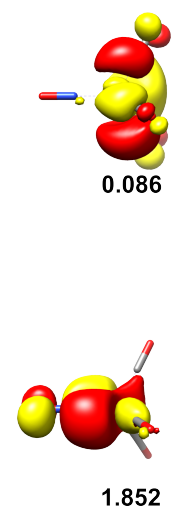
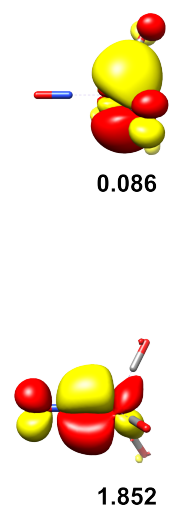
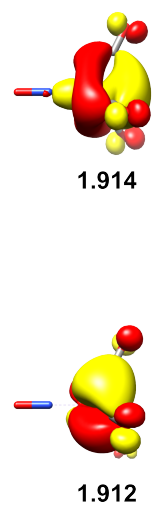

Figure S2: The $(10,10)^{\beta}$ active orbitals for the singlet state of complex 1 


\section{Iron(II) porphyrin}
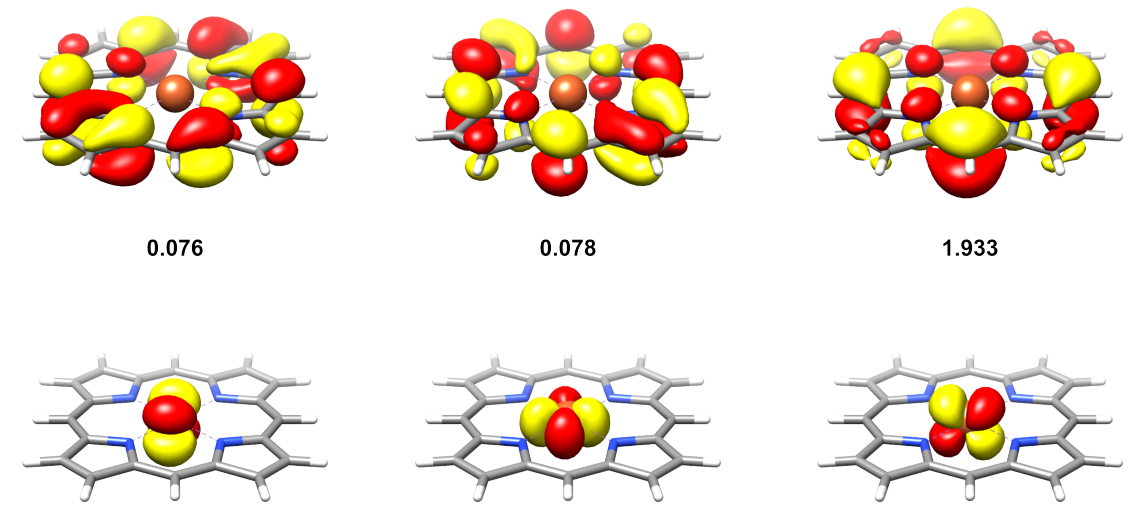

1.000

1.000

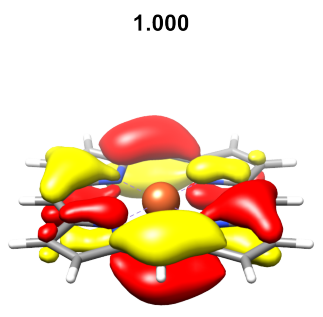

1.000

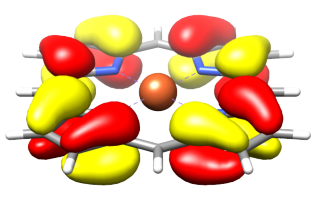

1.919

1.993

Figure S3: The $(10,9)$ active orbitals for the quintet state of complex 2 


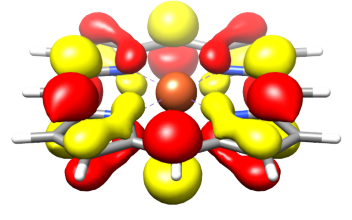

0.074

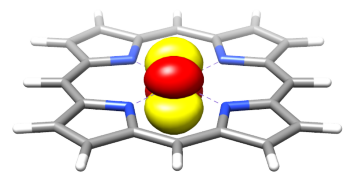

1.000

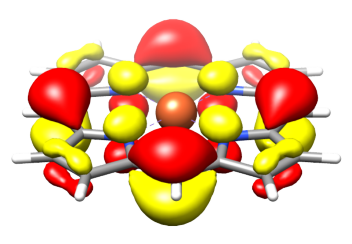

1.935

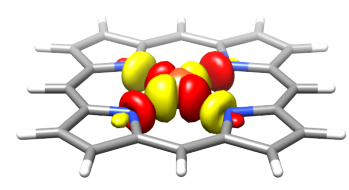

0.047

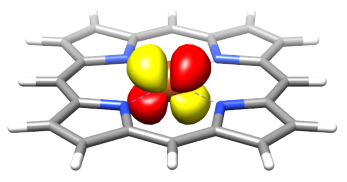

1.000

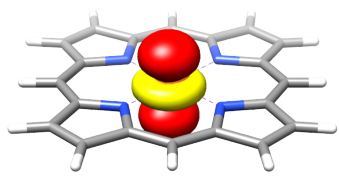

1.974

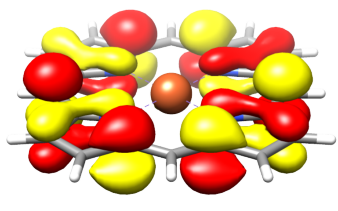

0.075

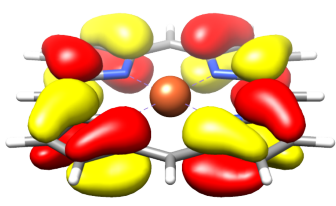

1.915

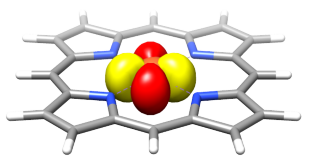

1.979

Figure S4: The $(10,9)$ active orbitals for the triplet state of complex $\mathbf{2}$

\section{Mixed-Valence Mn Dimer}

Deca-1,3,5,7,9-pentaene 


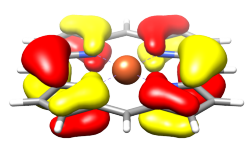

1.971

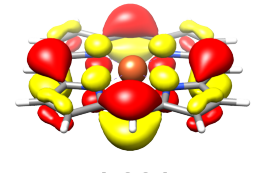

1.901

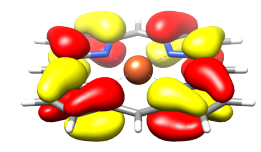

1.887

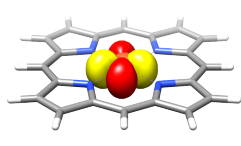

1.979

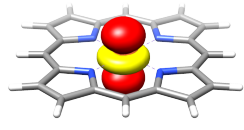

1.974

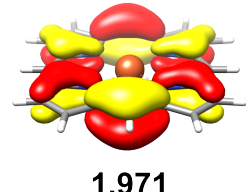

1.971

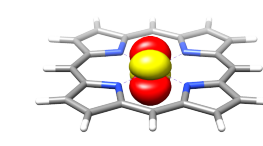

1.000

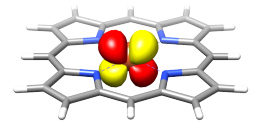

1.000

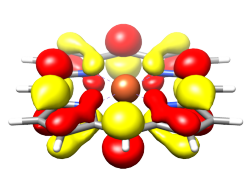

0.107

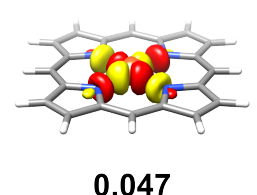

0.047

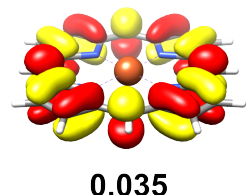

0.035

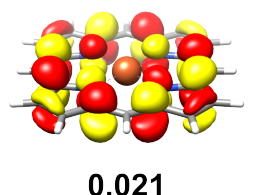

0.021

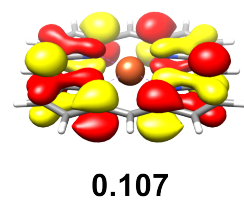

0.107

Figure S5: The $(14,13)$ active orbitals for the triplet state of complex 2 

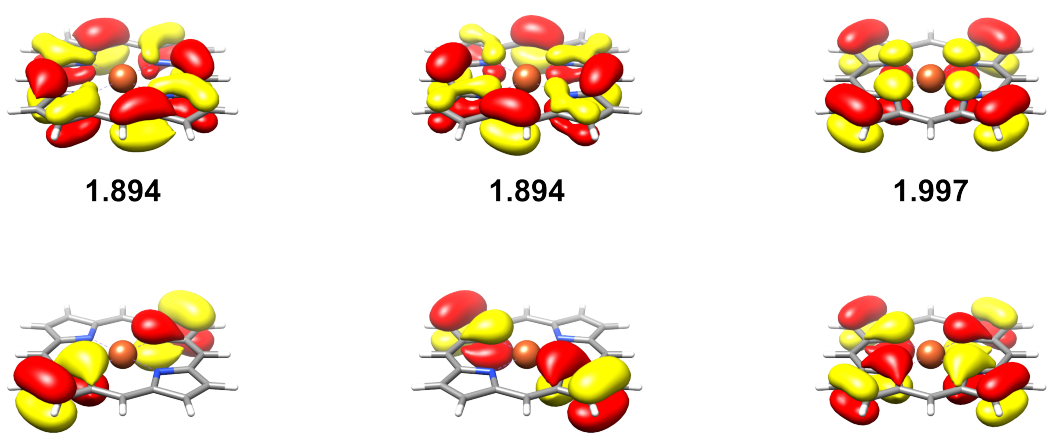

1.996

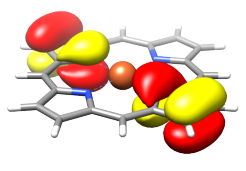

1.996
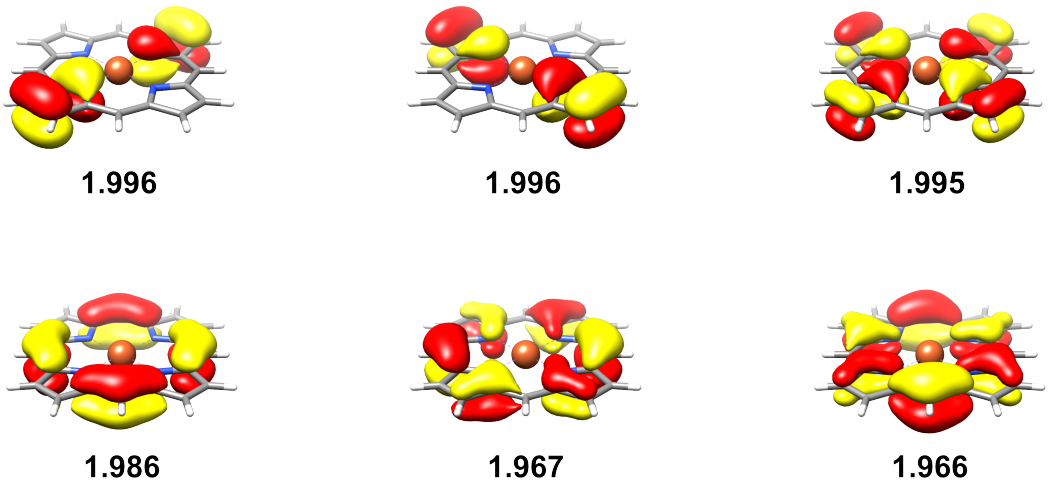

Figure S6: First part of the $(22,17)$ active orbitals for the quintet state of complex $\mathbf{2}$ 

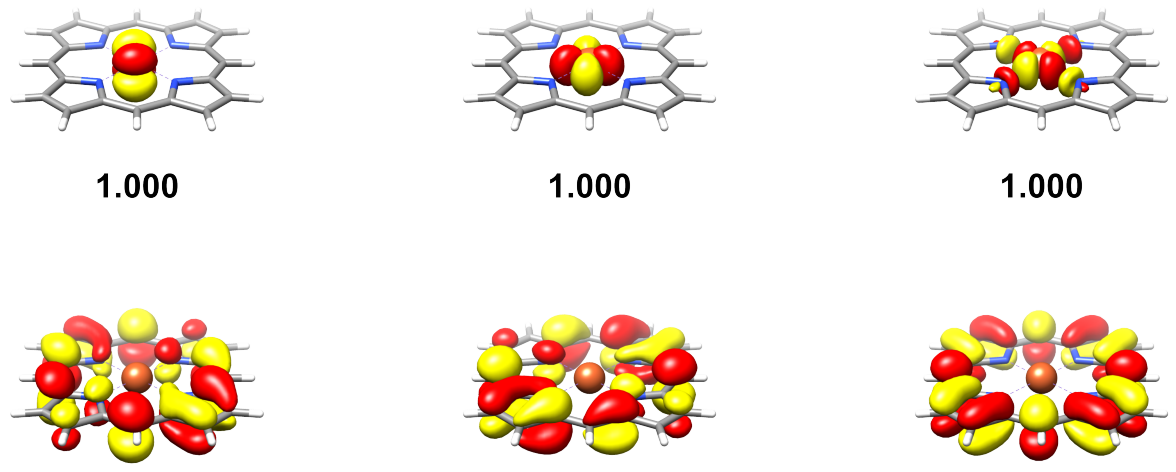

0.119

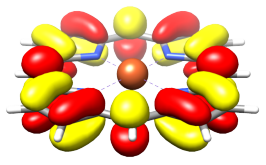

0.043
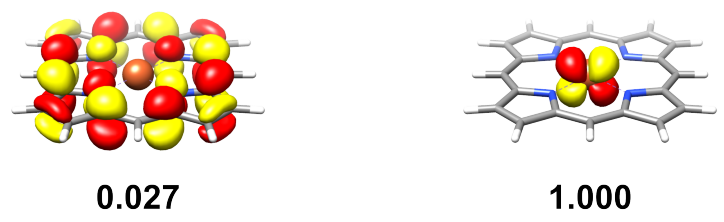

Figure S7: Second part of the $(22,17)$ active orbitals for the quintet state of complex $\mathbf{2}$ 

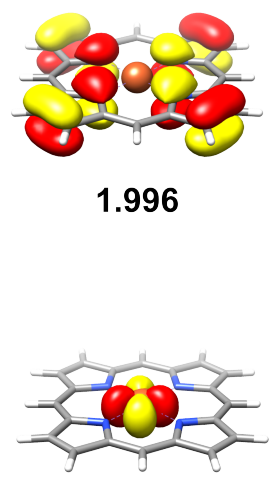

1.979
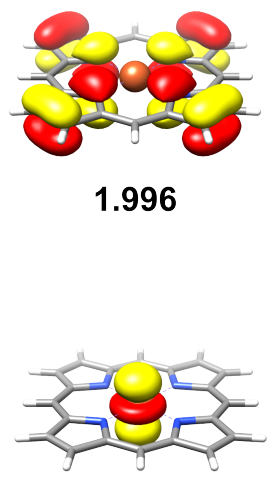

1.974
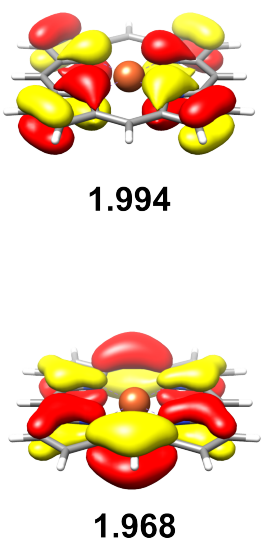
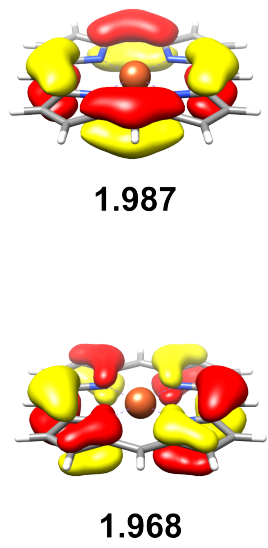
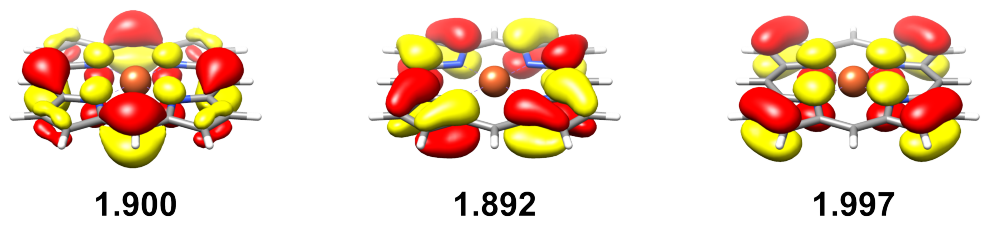

Figure S8: First part of the $(24,18)$ active orbitals for the triplet state of complex 2 

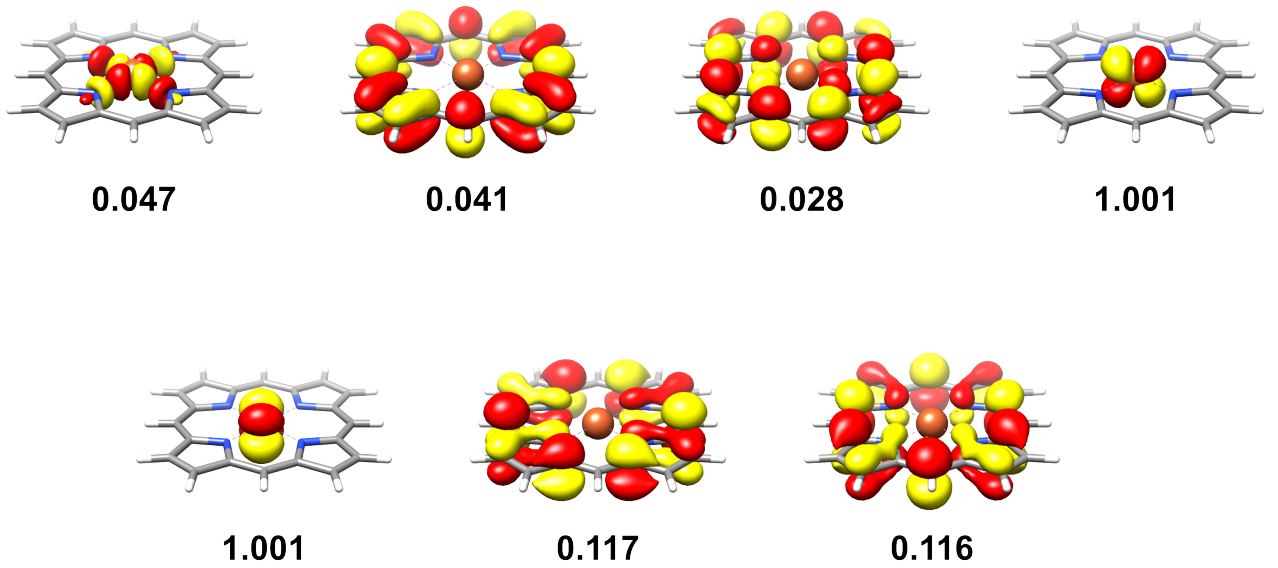

Figure S9: Second part of the $(24,18)$ active orbitals for the triplet state of complex 2 

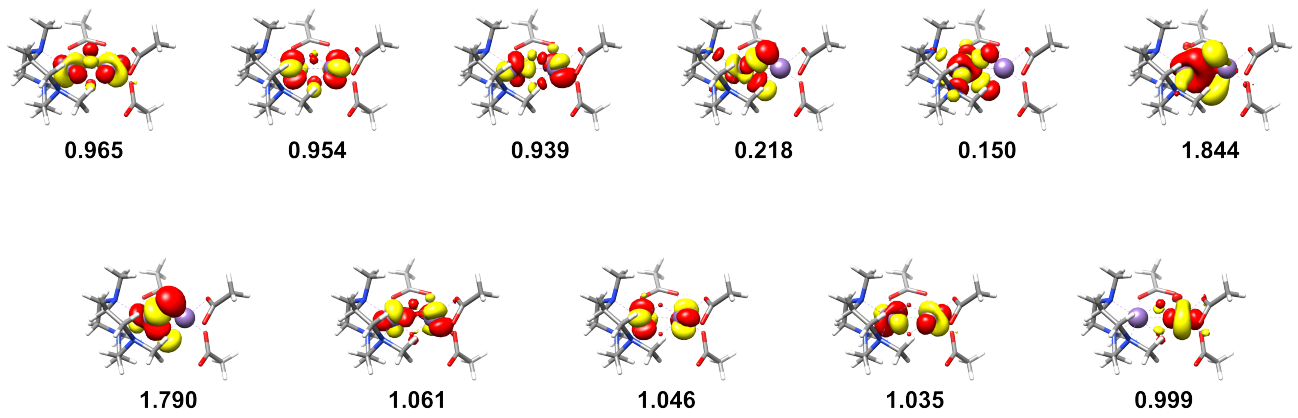

Figure S10: The $(11,11)$ active orbitals for the doublet state of complex $\mathbf{3}$ 

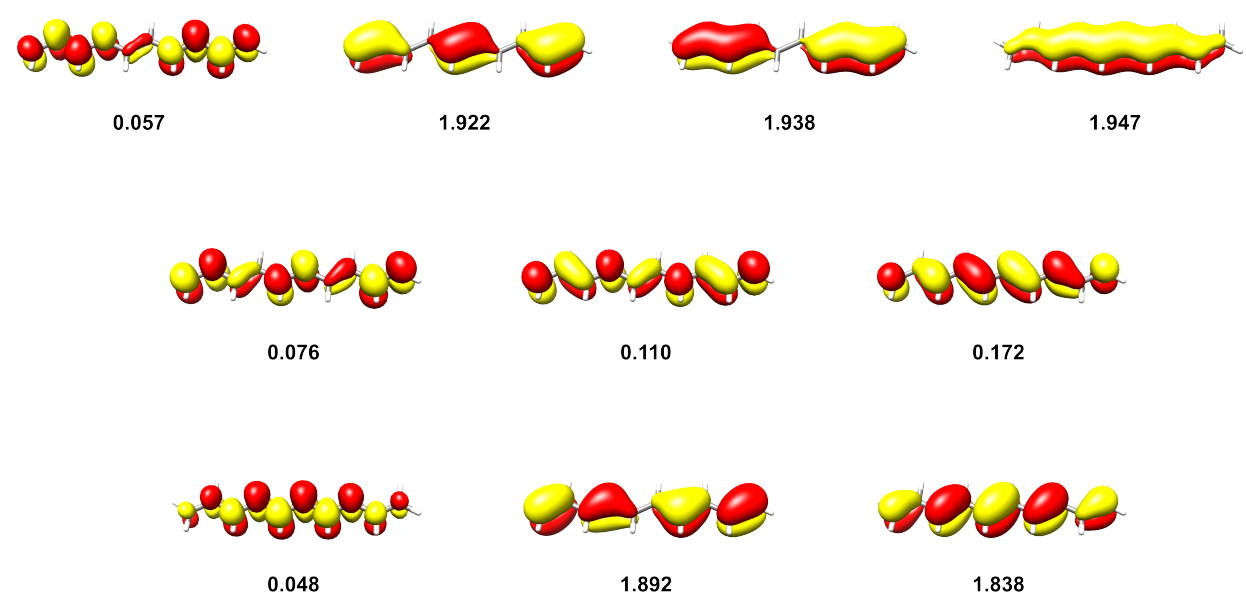

Figure S11: The $(10,10)$ active orbitals for molecule 4 


\section{C: Quasi-natural orbitals and their occupation numbers from an ASSIST calculation}

\section{Hieber Anion}

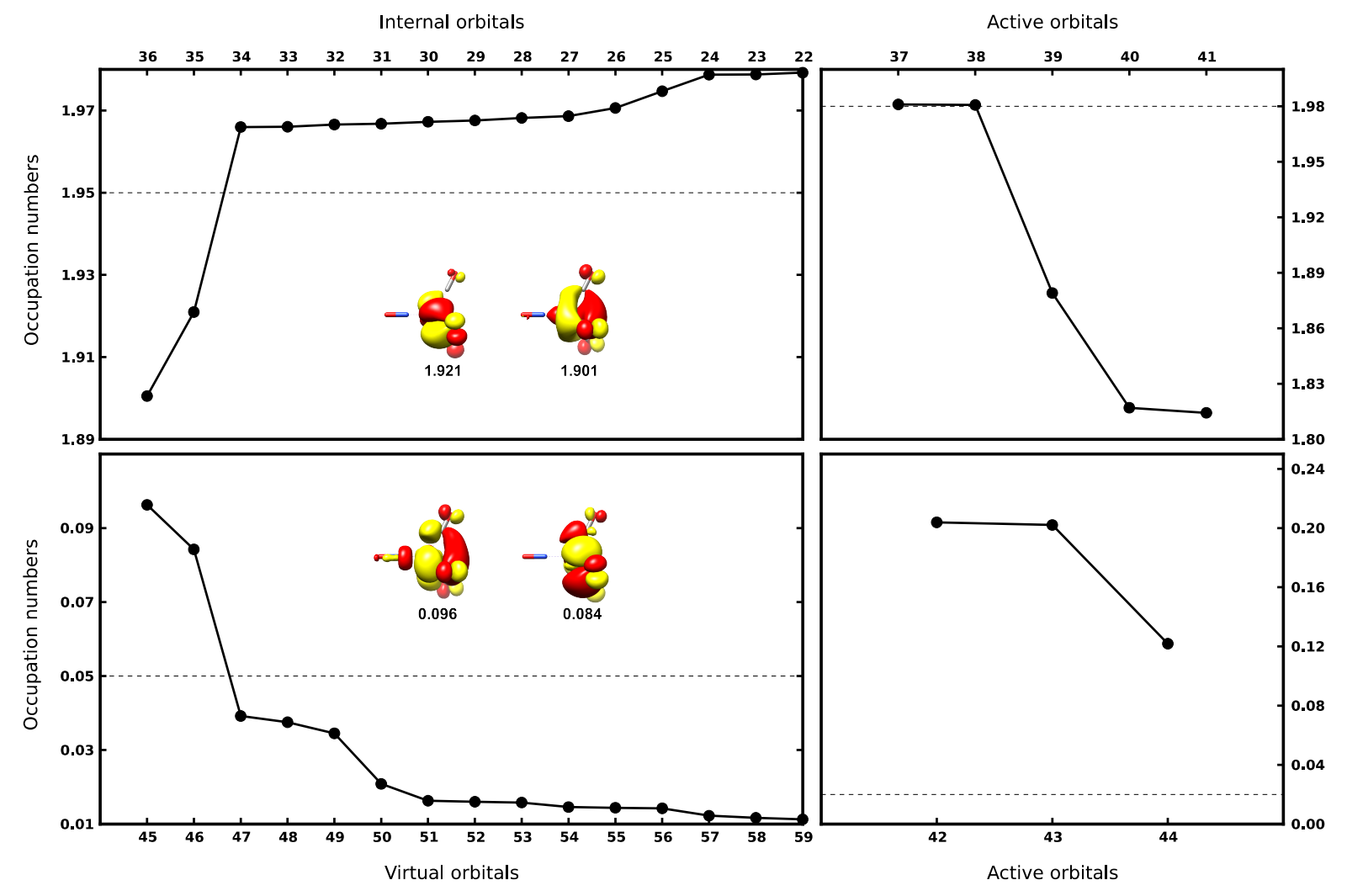

Figure S12: ASSIST $(10,8)$ for the singlet state of complex 1 


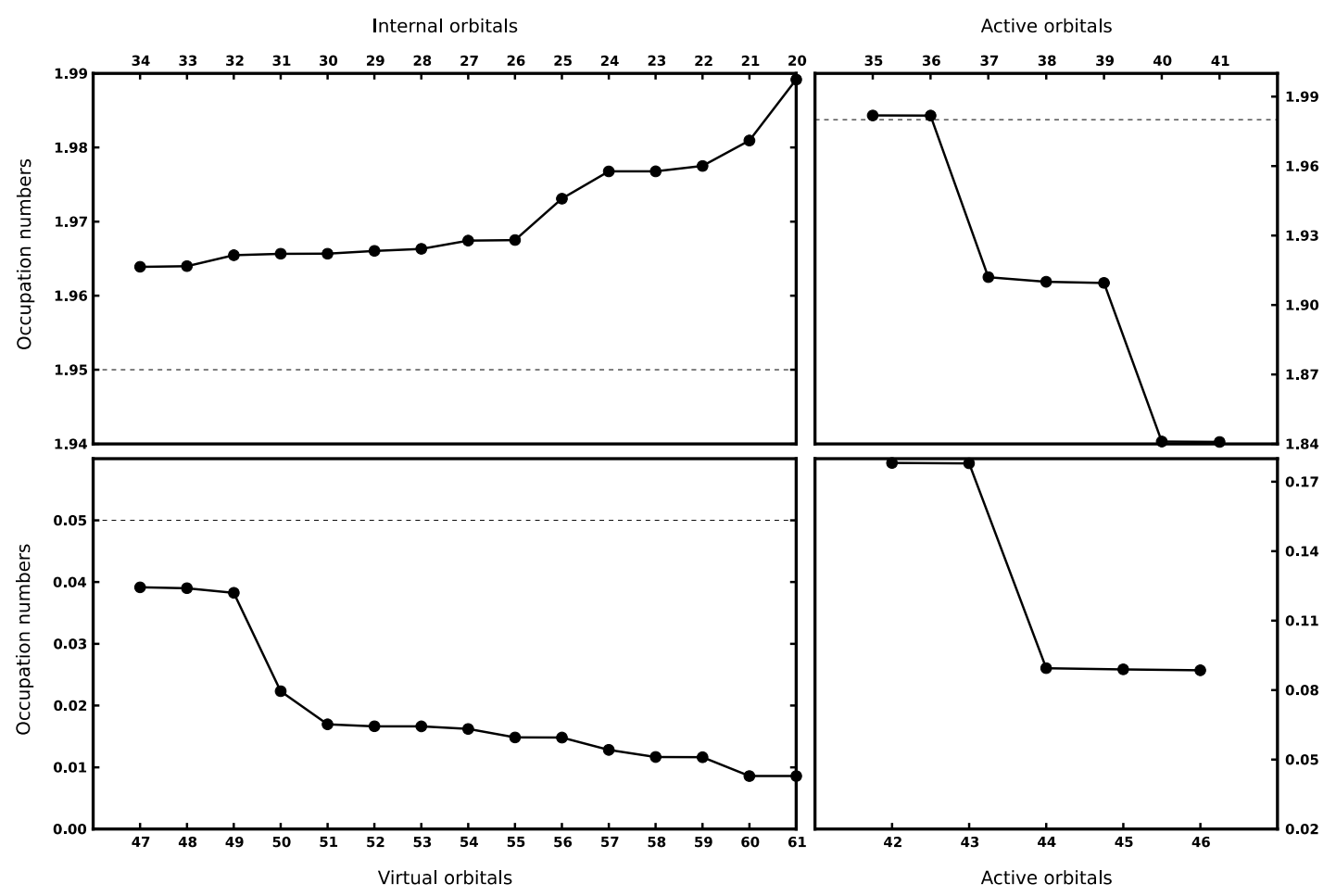

Figure S13: ASSIST $(14,12)$ for the singlet state of complex 1

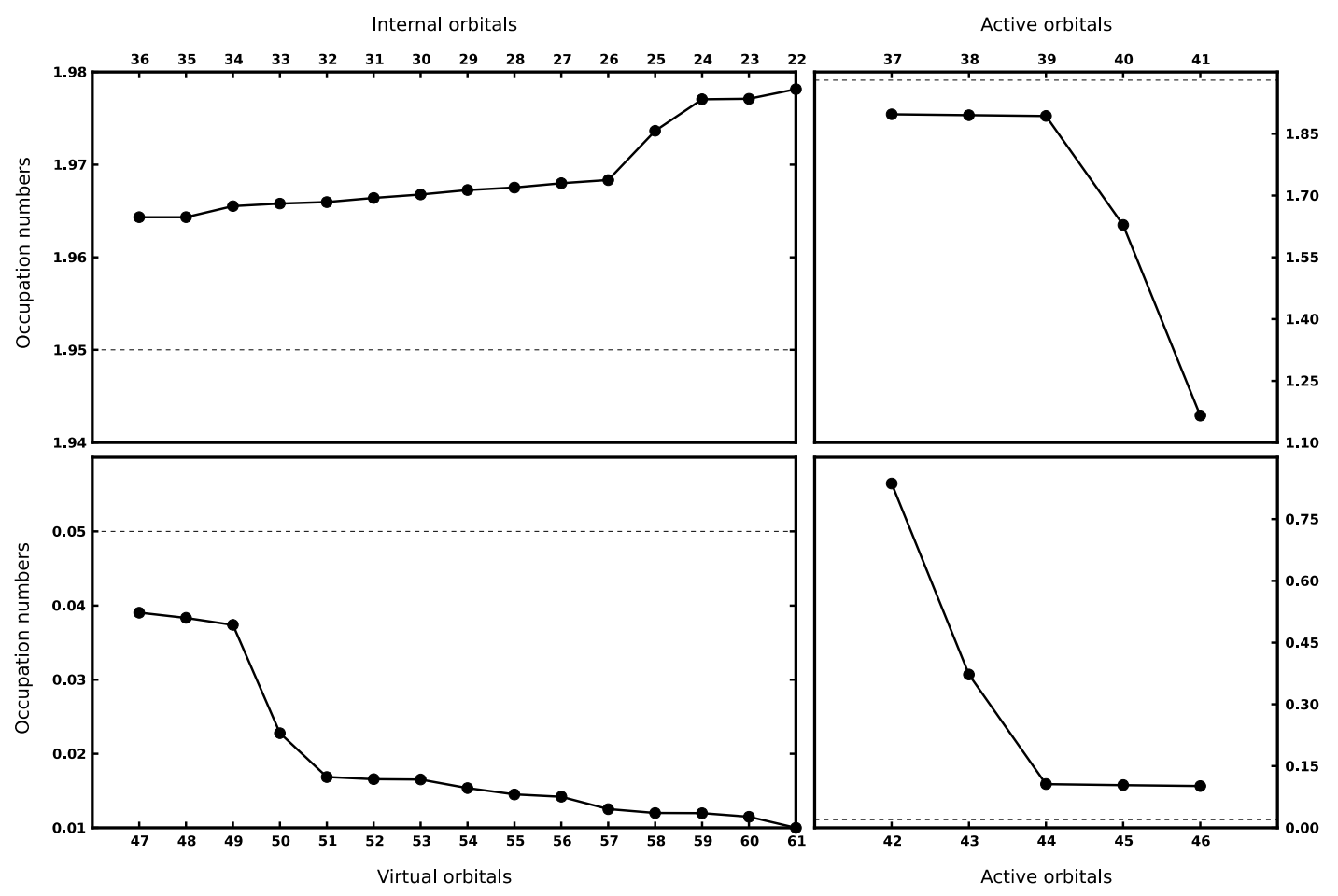

Figure S14: ASSIST $(10,10)$ for the triplet state of complex 1 


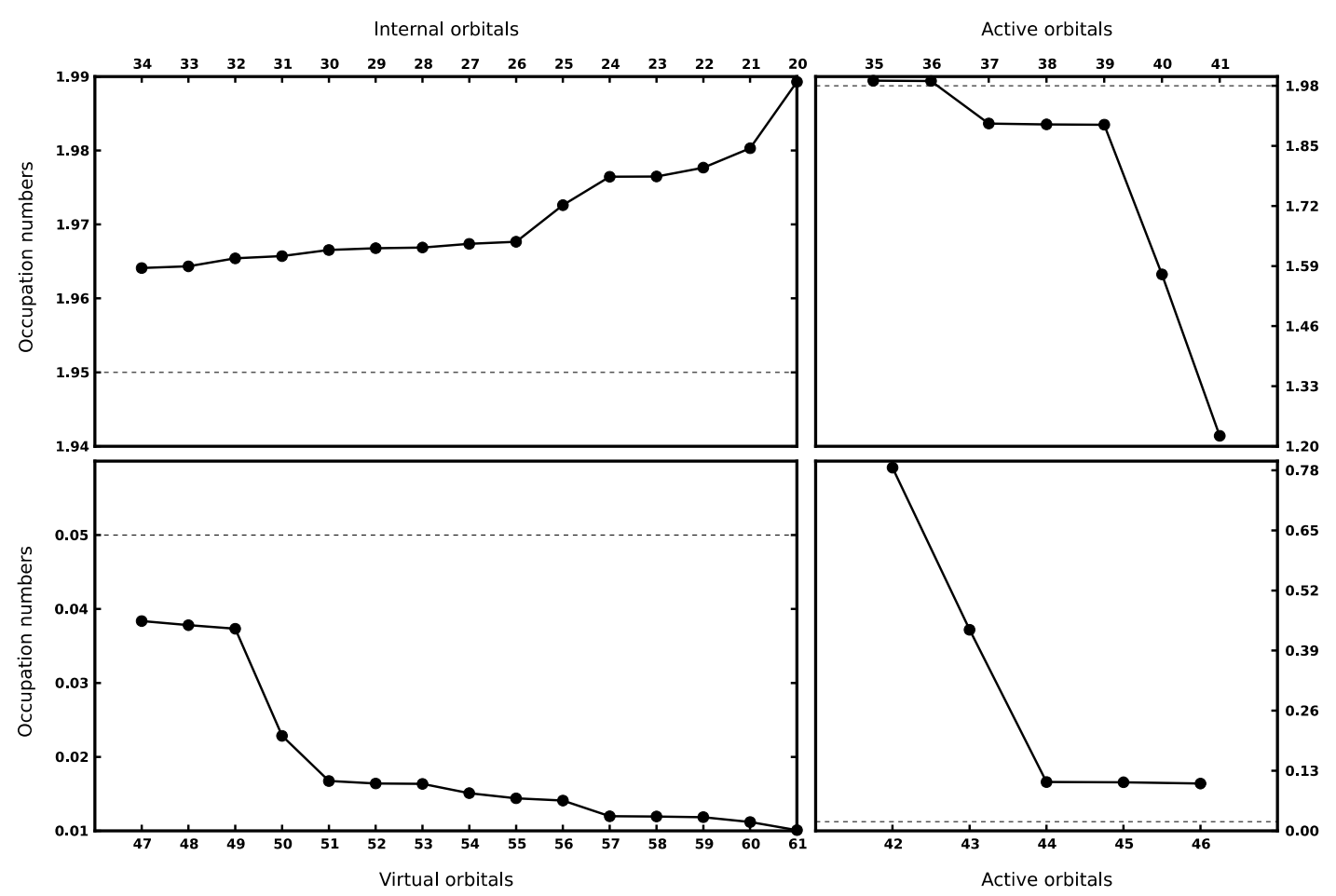

Figure S15: ASSIST $(14,12)$ for the triplet state of complex 1 


\section{Iron(II) porphyrin}

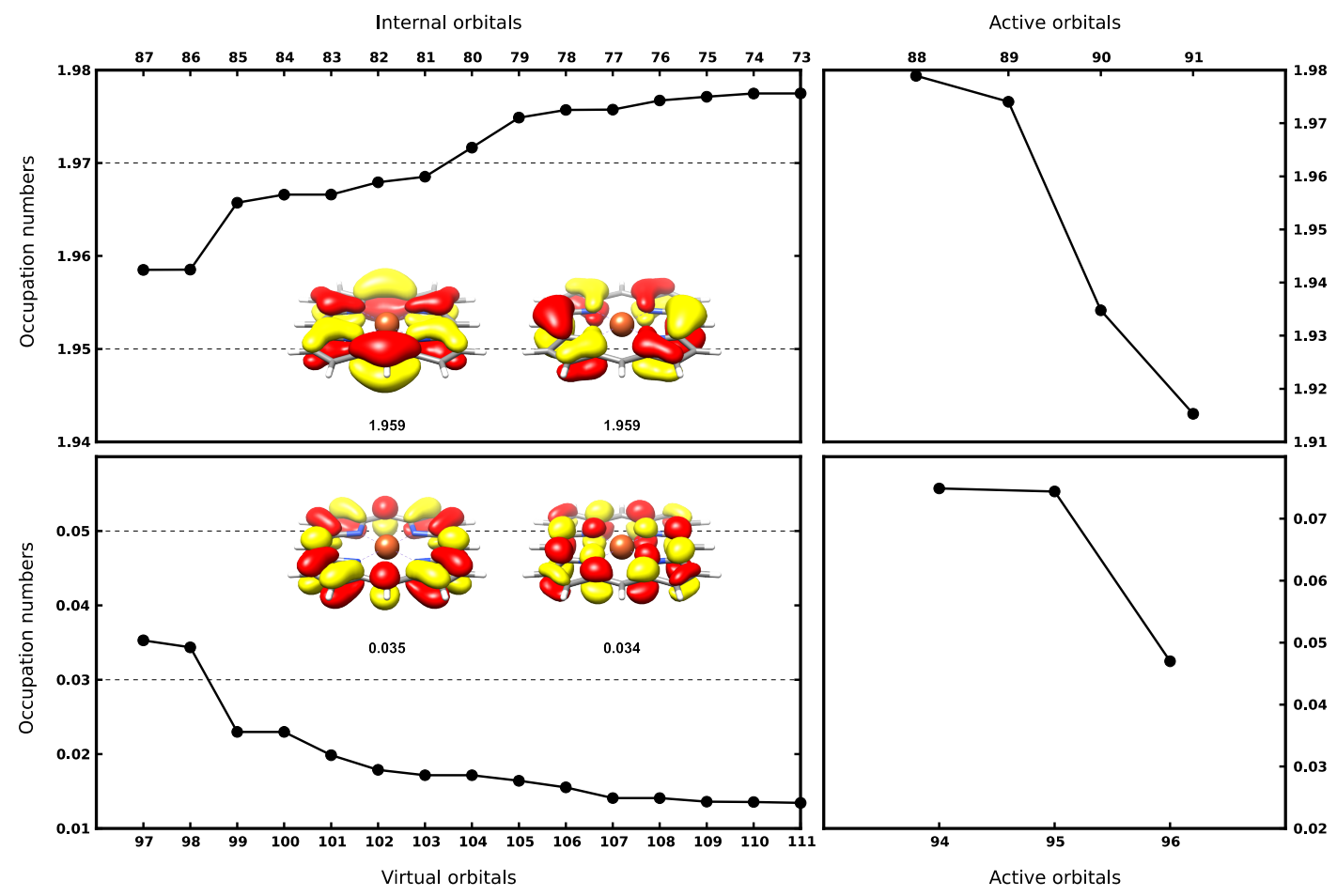

Figure S16: ASSIST $(10,9)$ for the triplet state of complex 2. Seven internal and two external orbitals are suggested with a relaxed threshold of $T_{\text {NOON }}=0.03$. 


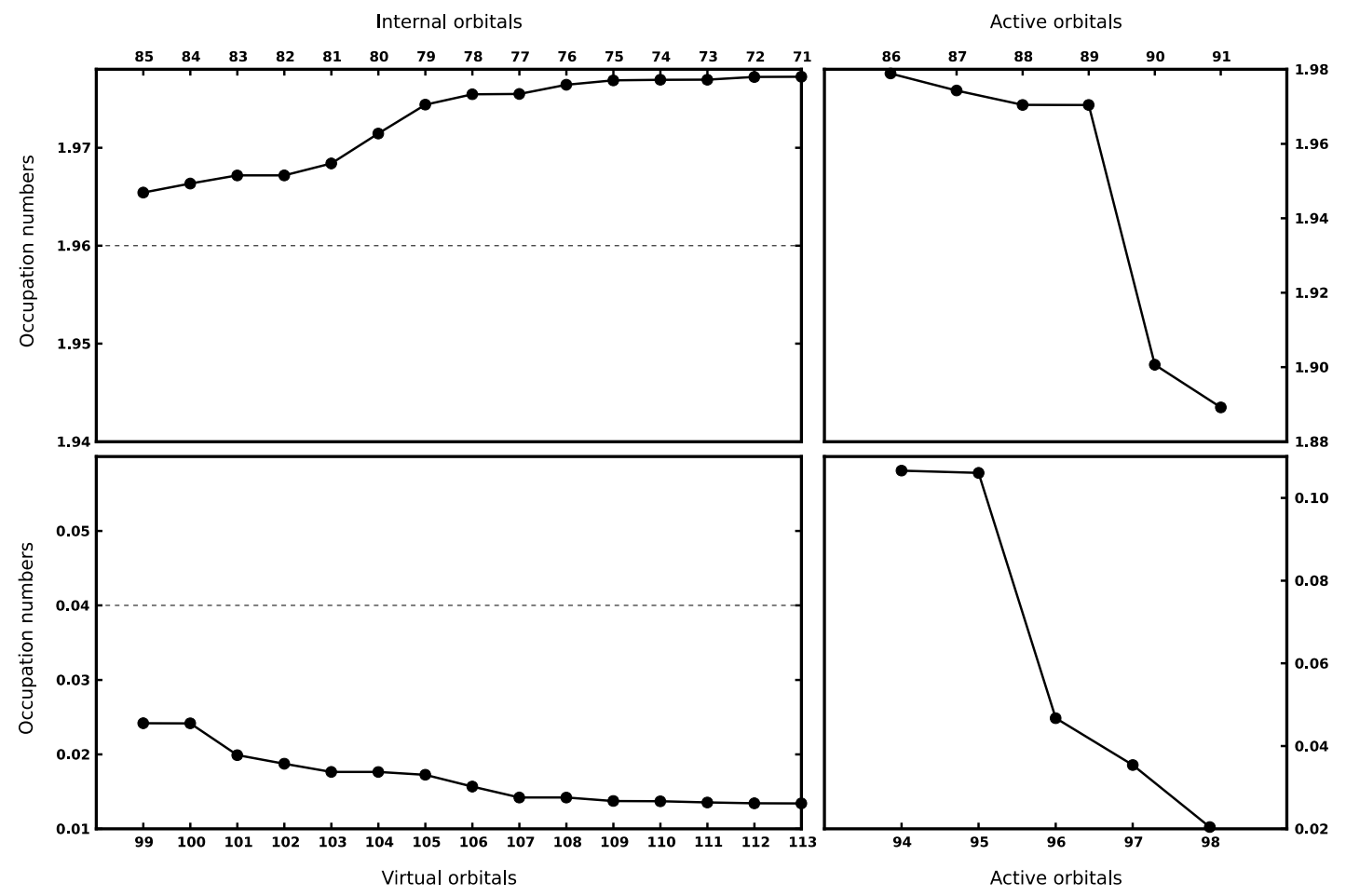

Figure S17: ASSIST $(14,13)$ for the triplet state of complex 2. No further orbitals are suggested for the active space with a threshold of $T_{N O O N}=0.04$ 


\section{Mixed-Valence Mn Dimer}

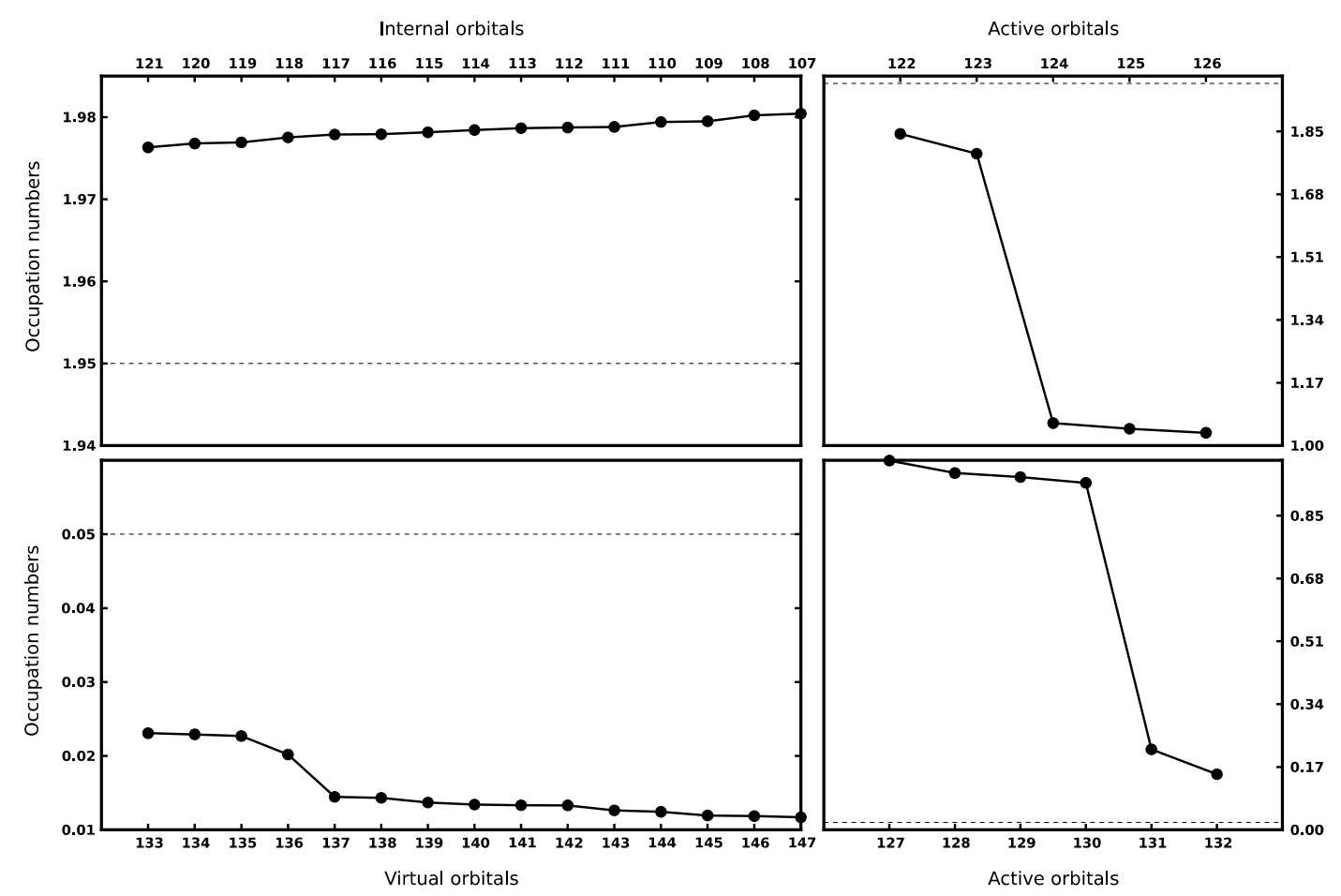

Figure S18: ASSIST $(11,11)$ for the doublet state of complex 3. No further orbitals are suggested for the active space. 


\section{Deca-1,3,5,7,9-pentaene}

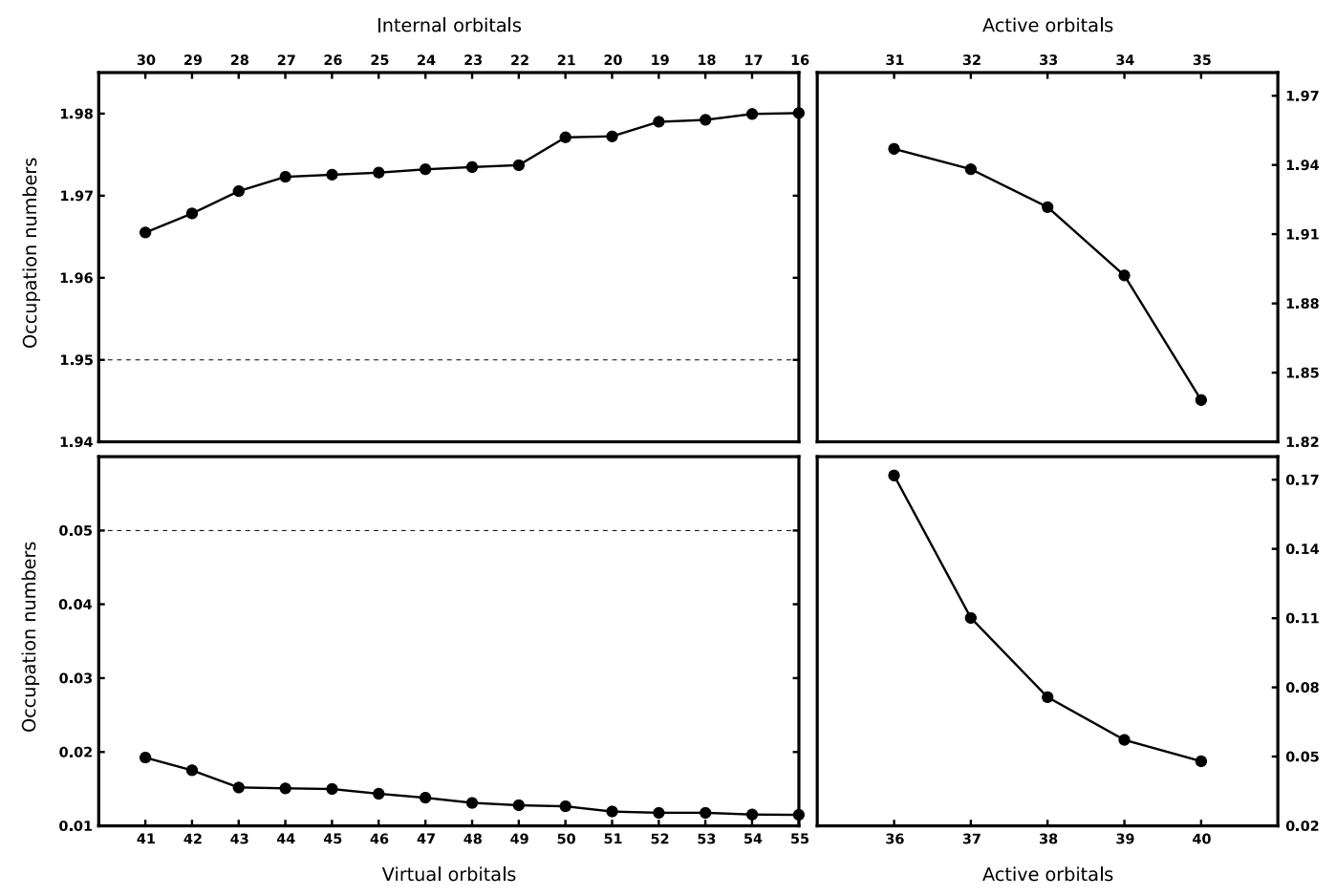

Figure S19: ASSIST $(10,10)$ for molecule 4. No further orbitals are suggested for the active space. 


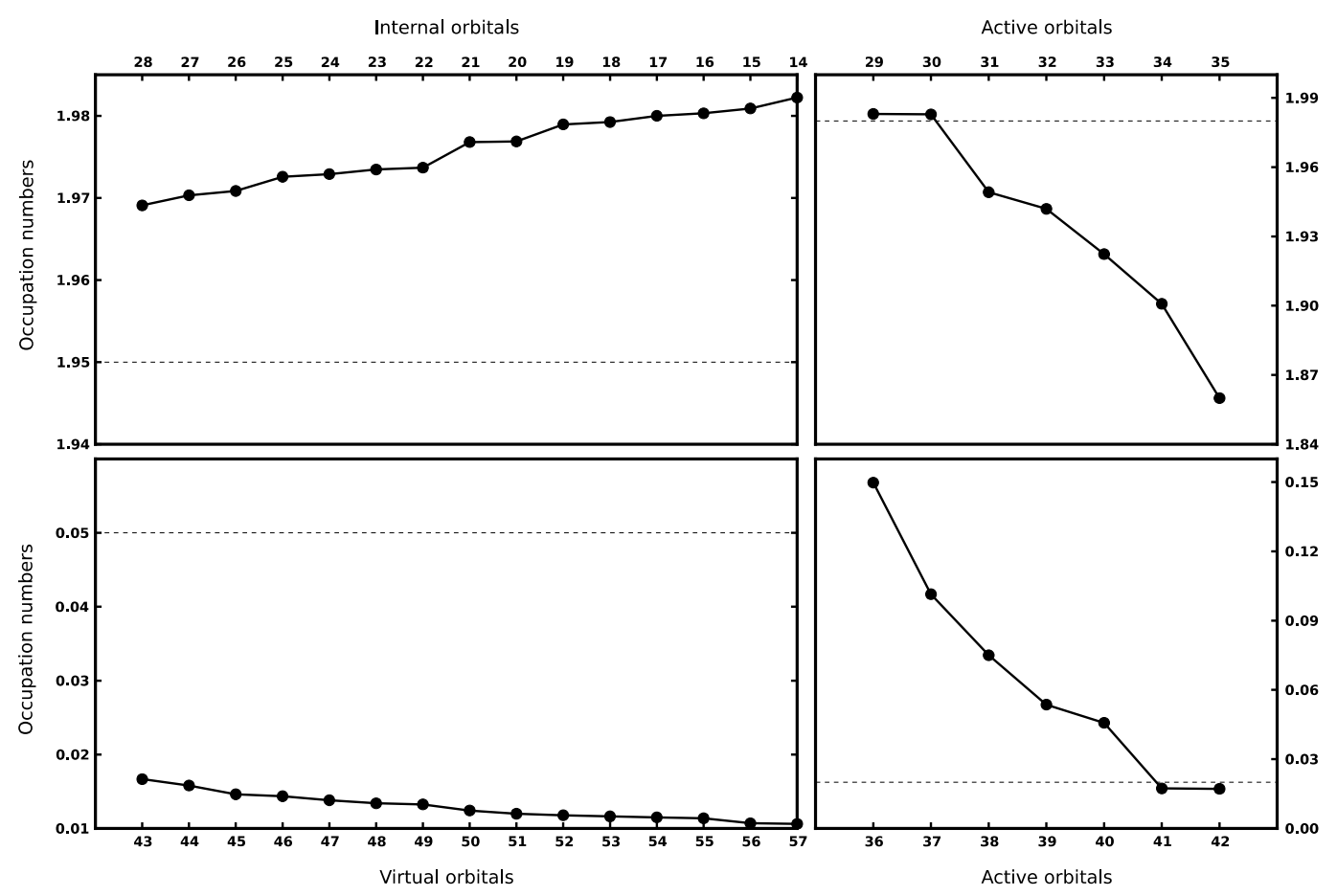

Figure S20: ASSIST $(14,14)$ for molecule 4. No further orbitals are suggested for the active space while two active orbitals have occupation numbers close to 2.0 and 0.0 , respectively. 


\section{D: CASSCF and SC-NEVPT2 Energies (in a.u)}

\section{Hieber Anion}

\begin{tabular}{cccc}
\hline Active Space & Multiplicity & CASSCF & SC-NEVPT2 \\
\hline$(8,5)$ & 1 & -1729.9099 & -1732.5651 \\
$(8,5)$ & 3 & -1729.8399 & -1732.4576 \\
$(10,8)$ & 1 & -1730.0736 & -1732.5217 \\
$(10,8)$ & 3 & -1729.9746 & -1732.3936 \\
$(10,10)^{\alpha}$ & 1 & -1730.2345 & -1732.4109 \\
$(10,10)^{\beta}$ & 1 & -1730.2345 & -1732.4106 \\
$(10,10)$ & 3 & -1730.1293 & -1732.3214 \\
$(14,12)$ & 1 & -1730.2510 & -1732.4084 \\
$(14,12)$ & 3 & -1730.1425 & -1732.3227 \\
$(16,13)$ & 1 & -1730.2722 & -1732.3145 \\
$(14,15)$ & 1 & -1730.3094 & \\
$(14,15)$ & 3 & -1730.2183 & \\
\hline
\end{tabular}

\section{Iron(II) porphyrin}

Calculations for the quintet and triplet states were performed with the geometries separately optimized for the respective states.

\section{Triplet}

\begin{tabular}{ccc}
\hline Active Space & CASSCF & SC-NEVPT2 \\
\hline$(10,9)$ & -2244.9821 & -2249.7887 \\
$(14,13)$ & -2245.0177 & -2249.7792 \\
$(24,18)$ & -2245.0299 & \\
\hline
\end{tabular}

\section{Quintet}

\begin{tabular}{ccc}
\hline Active Space & CASSCF & SC-NEVPT2 \\
\hline$(10,9)$ & -2245.0306 & -2249.8062 \\
$(14,13)$ & -2245.0733 & -2249.7951 \\
$(22,17)$ & -2245.0772 & \\
\hline
\end{tabular}




\section{Mixed-Valence Mn Dimer}

Energies for the different spin states for the active space of $(7,7)$ and $(11,11)$

\begin{tabular}{cccc}
\hline Multiplicity & CASSCF(7,7) & CASSCF(11,11) & SC-NEVPT2(11,11) \\
\hline 8 & -3647.9321 & -3648.0494 & -3654.3802 \\
6 & -3647.9321 & -3648.0492 & -3654.3800 \\
4 & -3647.9322 & -3648.0491 & -3654.3799 \\
2 & -3647.9322 & -3648.0491 & -3654.3799 \\
\hline
\end{tabular}

Deca-1,3,5,7,9-pentaene

\begin{tabular}{ccc}
\hline Active Space & CASSCF & SC-NEVPT2 \\
\hline$(6,6)$ & -385.8021 & -387.4671 \\
$(10,10)$ & -385.8601 & -387.4787 \\
$(14,14)$ & -385.9117 & \\
\hline
\end{tabular}




\section{E: Optimized XYZ Geometries}

\section{Hieber anion}

Charge $=-1$

$\begin{array}{rrrr}\mathrm{Fe} & 0.91198054431352 & -1.22501825372697 & -3.03193169954737 \\ \mathrm{C} & 2.06418099462322 & -2.57211496198120 & -2.89028112556033 \\ \mathrm{~N} & 1.31465781694778 & -0.03651724587127 & -4.09110765101162 \\ \mathrm{C} & -0.61334106924134 & -2.07298429480550 & -3.37135313342047 \\ \mathrm{C} & 0.70355792126154 & -0.75115929687576 & -1.32838800380558 \\ \mathrm{O} & -1.61164782651509 & -2.60575981610975 & -3.62376489002435 \\ \mathrm{O} & 0.57539742797786 & -0.41683615499019 & -0.22559692749194 \\ \mathrm{O} & 1.60193424186987 & 0.81974484612463 & -4.86130033995096 \\ \mathrm{O} & 2.83485194876265 & -3.43566782176399 & -2.82359422918739\end{array}$




\section{Iron(II) porphyrin}

Charge $=0$, Multiplicity $=3$

$\begin{array}{rrrr}\mathrm{Fe} & 0.00000355892674 & -0.00000103098421 & 0.00085866406605 \\ \mathrm{~N} & 1.41424758945786 & 1.41576786338957 & 0.00031964151663 \\ \mathrm{~N} & -1.41424670327107 & 1.41576722236744 & 0.00031980716484 \\ \mathrm{~N} & 1.41424758607561 & -1.41576836957529 & 0.00031983225990 \\ \mathrm{~N} & -1.41424665719763 & -1.41576790108557 & 0.00031980738036 \\ \mathrm{C} & -0.00000026842211 & 3.41454833264043 & 0.00007858930049 \\ \mathrm{C} & -0.00000016980179 & -3.41454882392625 & 0.00007858867572 \\ \mathrm{C} & 3.41100235065548 & 0.00000008486487 & 0.00006317205189 \\ \mathrm{C} & -3.41100252752052 & 0.00000013856115 & 0.00006325670831 \\ \mathrm{C} & 2.49372793898475 & 3.45525404294899 & -0.00009465214390 \\ \mathrm{C} & -2.49372843829452 & 3.45525360232711 & -0.00009472250712 \\ \mathrm{C} & 2.49372845835254 & -3.45525395379495 & -0.00009446765700 \\ \mathrm{C} & -2.49372885379753 & -3.45525346855392 & -0.00009475085697 \\ \mathrm{C} & 3.45209939494783 & 2.49450158208033 & -0.00009814905998 \\ \mathrm{C} & -3.45209938416499 & 2.49450070015424 & -0.00009791749238 \\ \mathrm{C} & 3.45209959758774 & -2.49450116921480 & -0.00009809363025 \\ \mathrm{C} & -3.45209952327470 & -2.49450012749111 & -0.00009791336872 \\ \mathrm{C} & 1.22556786118056 & 2.77797457585306 & 0.00011189117661 \\ \mathrm{C} & -1.22556825351908 & 2.77797421827094 & 0.00011215886785 \\ \mathrm{C} & 1.22556813824076 & -2.77797505804840 & 0.00011196350572 \\ \mathrm{C} & -1.22556839494260 & -2.77797487577715 & 0.00011206030646 \\ \mathrm{C} & 2.77416776063370 & 1.22592863648539 & 0.00010363588859 \\ \mathrm{C} & -2.77416712189585 & 1.22592817687011 & 0.00010361580627 \\ \mathrm{C} & 2.77416766067499 & -1.22592851568260 & 0.00010399080000 \\ \mathrm{C} & -2.77416699469254 & -1.22592798702668 & 0.00010381637280 \\ \mathrm{H} & -0.00000070680996 & 4.49643563085488 & -0.00011187837263 \\ \mathrm{H} & -0.00000047450475 & -4.49643608634550 & -0.00011205996453 \\ \mathrm{H} & 4.49289898315457 & 0.00000000934290 & -0.00013009806437 \\ \mathrm{H} & -4.49289914889900 & 0.00000005011939 & -0.00013001848759 \\ \mathrm{H} & 4.52383102930609 & 2.61647571857777 & -0.00025787550771 \\ \mathrm{H} & -4.52383115808232 & 2.61647372056264 & -0.00025794918605 \\ \mathrm{H} & 4.52383128372773 & -2.61647470003095 & -0.00025783129670 \\ \mathrm{H} & -4.52383135598303 & -2.61647265194035 & -0.00025783208989 \\ \mathrm{H} & 2.61701427910907 & 4.52668711178205 & -0.00024943845727 \\ \mathrm{H} & -2.61701567937509 & 4.52668658949472 & -0.00024957310997 \\ \mathrm{H} & 2.61701500743690 & -4.52668695834325 & -0.00024951915067 \\ \mathrm{H} & -2.61701666400384 & -4.52668632972700 & -0.00024975144479\end{array}$


Charge $=0$, Multiplicity $=5$

$\begin{array}{rrrr}\mathrm{Fe} & 0.00000198931060 & 0.00000237386987 & -0.00001615834052 \\ \mathrm{~N} & 1.45711594298951 & 1.45710401029993 & -0.00000659714199 \\ \mathrm{~N} & -1.45711524346773 & 1.45710363922074 & -0.00000618745067 \\ \mathrm{~N} & 1.45711501210230 & -1.45710217046391 & -0.00000671180030 \\ \mathrm{~N} & -1.45711421989575 & -1.45710175495267 & -0.00000577793220 \\ \mathrm{C} & -0.00000015681027 & 3.42939879073583 & -0.00000041138190 \\ \mathrm{C} & -0.00000015402506 & -3.42939809026848 & -0.00000098971745 \\ \mathrm{C} & 3.42941645407351 & -0.00000029599232 & -0.00000045525813 \\ \mathrm{C} & -3.42941608870352 & -0.00000029325619 & -0.00000044609865 \\ \mathrm{C} & 2.52276107610192 & 3.48571714030716 & 0.00000326728306 \\ \mathrm{C} & -2.52276157668883 & 3.48571664708571 & 0.00000086633999 \\ \mathrm{C} & 2.52275961005484 & -3.48571732876437 & 0.00000383992596 \\ \mathrm{C} & -2.52276006632815 & -3.48571680857618 & 0.00000165418296 \\ \mathrm{C} & 3.48572188619396 & 2.52276349353958 & 0.00000192057331 \\ \mathrm{C} & -3.48572203942165 & 2.52276278712483 & 0.00000310686330 \\ \mathrm{C} & 3.48572071450252 & -2.52276428088340 & 0.00000073262969 \\ \mathrm{C} & -3.48572079887723 & -2.52276350635004 & 0.00000149074364 \\ \mathrm{C} & 1.24827498910031 & 2.80992969345102 & -0.00000230665072 \\ \mathrm{C} & -1.24827517538879 & 2.80992945635403 & -0.00000264122953 \\ \mathrm{C} & 1.24827422605291 & -2.80992857464327 & -0.00000235335016 \\ \mathrm{C} & -1.24827437067557 & -2.80992834489559 & -0.00000248178871 \\ \mathrm{C} & 2.80994295611823 & 1.24827290893271 & -0.00000206699514 \\ \mathrm{C} & -2.80994240002208 & 1.24827258245940 & -0.00000183893922 \\ \mathrm{C} & 2.80994232673209 & -1.24827298655786 & -0.00000266648223 \\ \mathrm{C} & -2.80994167818281 & -1.24827259039753 & -0.00000207170347 \\ \mathrm{H} & -0.00000035731721 & 4.51223093556664 & 0.00000021147422 \\ \mathrm{H} & -0.00000038390933 & -4.51223069273717 & 0.00000048866262 \\ \mathrm{H} & 4.51224908040334 & -0.00000092426956 & 0.00000041554564 \\ \mathrm{H} & -4.51224879861216 & -0.00000094166117 & 0.00000099872642 \\ \mathrm{H} & 4.55626727717120 & 2.65730810985477 & 0.00000480868749 \\ \mathrm{H} & -4.55626759752125 & 2.65730674462625 & 0.00000749268028 \\ \mathrm{H} & 4.55626605908195 & -2.65730992741617 & 0.00000291558175 \\ \mathrm{H} & -4.55626630753878 & -2.65730853232584 & 0.00000479148642 \\ \mathrm{H} & 2.65729777749578 & 4.55626329132121 & 0.00000718059727 \\ \mathrm{H} & -2.65729885996256 & 4.55626273172215 & 0.00000269153083 \\ \mathrm{H} & 2.65729542990194 & -4.55626393594891 & 0.00000860214156 \\ \mathrm{H} & -2.65729653403817 & -4.55626335611119 & 0.00000468660457\end{array}$




\section{Mixed-Valence Mn Dimer}

Charge $=0$

$\begin{array}{crrr}\mathrm{Mn} & 0.892056 & 0.900246 & 0.119802 \\ \mathrm{Mn} & -1.043613 & -0.929330 & 0.212248 \\ \mathrm{O} & -0.888111 & 0.929295 & -0.036156 \\ \mathrm{O} & 0.803307 & -0.857408 & -0.037556 \\ \mathrm{O} & 0.882748 & 0.911790 & 2.065203 \\ \mathrm{O} & -0.783643 & -0.573208 & 2.437207 \\ \mathrm{C} & 0.054074 & 0.260239 & 2.811537 \\ \mathrm{C} & 0.185738 & 0.589769 & 4.278806 \\ \mathrm{H} & 0.966603 & 1.330469 & 4.460652 \\ \mathrm{H} & -0.774536 & 0.964643 & 4.646945 \\ \mathrm{H} & 0.408242 & -0.326324 & 4.834654 \\ \mathrm{O} & -3.022670 & -0.877583 & 0.465391 \\ \mathrm{O} & -2.861693 & -0.721701 & -1.709359 \\ \mathrm{O} & -1.067487 & -2.867941 & 0.351844 \\ \mathrm{~N} & 3.035590 & 0.914262 & 0.134302 \\ \mathrm{~N} & 1.168459 & 3.011257 & 0.214771 \\ \mathrm{~N} & 1.126533 & 1.206592 & -1.918881 \\ \mathrm{O} & -0.336564 & -3.214346 & -1.712185 \\ \mathrm{C} & 3.548569 & 2.300645 & 0.338462 \\ \mathrm{C} & 2.493226 & 3.172939 & 0.925937 \\ \mathrm{C} & 1.195260 & 3.566636 & -1.157911 \\ \mathrm{C} & 0.599316 & 2.626658 & -2.121885 \\ \mathrm{C} & 2.570532 & 1.110032 & -2.293973 \\ \mathrm{C} & 3.345296 & 0.385420 & -1.245481 \\ \mathrm{C} & 3.598079 & -0.008469 & 1.154440 \\ \mathrm{C} & 0.072038 & 3.658253 & 0.998546 \\ \mathrm{C} & 0.324927 & 0.261383 & -2.729618 \\ \mathrm{C} & -0.640338 & -3.623177 & -0.616058 \\ \mathrm{C} & -0.524949 & -5.096658 & -0.243869 \\ \mathrm{C} & -3.556285 & -0.766578 & -0.692257 \\ \mathrm{C} & -5.051793 & -0.698540 & -0.758044 \\ \mathrm{H} & 4.427878 & 2.285283 & 0.991999 \\ \mathrm{H} & 3.885408 & 2.690250 & -0.628627 \\ \mathrm{H} & 2.293015 & 2.879575 & 1.959473 \\ \mathrm{H} & 2.804919 & 4.227737 & 0.915817 \\ & 0.237429 & 3.787814 & -1.418345 \\ & & & -1.188789\end{array}$




$\begin{array}{rrrr}\mathrm{H} & -0.478651 & 2.531845 & -1.963165 \\ \mathrm{H} & 0.779005 & 2.939867 & -3.159221 \\ \mathrm{H} & 2.961403 & 2.122804 & -2.442091 \\ \mathrm{H} & 2.665073 & 0.590245 & -3.252680 \\ \mathrm{H} & 3.040893 & -0.664902 & -1.217515 \\ \mathrm{H} & 4.425895 & 0.439709 & -1.442364 \\ \mathrm{H} & 3.375722 & 0.391964 & 2.144286 \\ \mathrm{H} & 4.683279 & -0.110014 & 1.019303 \\ \mathrm{H} & 3.100494 & -0.974094 & 1.045824 \\ \mathrm{H} & 0.061906 & 3.225967 & 1.998504 \\ \mathrm{H} & -0.874720 & 3.424015 & 0.509351 \\ \mathrm{H} & 0.233626 & 4.743110 & 1.048608 \\ \mathrm{H} & -0.722528 & 0.324370 & -2.426222 \\ \mathrm{H} & 0.666254 & -0.756709 & -2.531763 \\ \mathrm{H} & 0.435249 & 0.510354 & -3.793763 \\ \mathrm{H} & -0.275251 & -5.685631 & -1.127872 \\ \mathrm{H} & -1.461313 & -5.452902 & 0.196798 \\ \mathrm{H} & 0.257699 & -5.216492 & 0.513632 \\ \mathrm{H} & -5.374623 & -0.452353 & -1.770706 \\ \mathrm{H} & -5.431587 & 0.042776 & -0.047581 \\ \mathrm{H} & -5.474023 & -1.668013 & -0.469920\end{array}$




\section{Deca-1,3,5,7,9-pentaene}

Charge $=0$

$\begin{array}{lrrr}\mathrm{C} & 0.67618876607775 & -0.01143090574869 & 0.00000042100608 \\ \mathrm{C} & -0.67618928652313 & 0.01142918784461 & 0.00000056127566 \\ \mathrm{C} & 1.46434460817891 & -1.20723823463763 & 0.00000031069222 \\ \mathrm{C} & -1.46434433154212 & 1.20723685099934 & 0.00000026640177 \\ \mathrm{C} & 2.81423468703995 & -1.23321982920757 & -0.00000053269875 \\ \mathrm{C} & -2.81423459435864 & 1.23321994697388 & -0.00000017354917 \\ \mathrm{C} & 3.60049731838260 & -2.44091745351423 & -0.00000084191783 \\ \mathrm{C} & -3.60049737386634 & 2.44091781464749 & -0.00000038032185 \\ \mathrm{C} & 4.93835684979871 & -2.47575201344374 & 0.00000026648662 \\ \mathrm{C} & -4.93835678472673 & 2.47575332800395 & -0.00000004131407 \\ \mathrm{H} & 1.21385527900219 & 0.93367275310346 & 0.00000023689911 \\ \mathrm{H} & -1.21385578793082 & -0.93367438813952 & 0.00000049434323 \\ \mathrm{H} & 0.92523625651410 & -2.15173833813871 & 0.00000107770062 \\ \mathrm{H} & -0.92523511846252 & 2.15173636817883 & 0.00000025431470 \\ \mathrm{H} & 3.35818809230969 & -0.29178078345680 & -0.00000106438544 \\ \mathrm{H} & -3.35818854186832 & 0.29178108882586 & -0.00000004569312 \\ \mathrm{H} & 3.04745293282861 & -3.37667431398586 & -0.00000120617739 \\ \mathrm{H} & -3.04745312358046 & 3.37667479356188 & -0.00000036154573 \\ \mathrm{H} & 5.52653169935210 & -1.56523155121983 & 0.00000108329005 \\ \mathrm{H} & 5.48124390723857 & -3.41112935076796 & -0.00000009381538 \\ \mathrm{H} & -5.48124233873208 & 3.41113153459913 & -0.00000010365654 \\ \mathrm{H} & -5.52653311513202 & 1.56523349552210 & -0.00000012733479\end{array}$

